\title{
Implementasi Metode Fis Mamdani Pada Aplikasi Jadwal Mengajar Guru Di SMK Adi Luhur 2 Jakarta
}

\author{
Imam Sunoto ${ }^{1}$ Lukman $^{2} ;$ Julizal $^{3}$ \\ 1, 2, 3 FTIK, Universitas Indraprasta PGRI \\ ${ }^{1}$ raidersimam@gmail.com \\ ${ }^{2} 1 \mathrm{kmnaja51@gmail.com}$ \\ 3julizal.ram@gmail.com
}

\begin{abstract}
Setting teacher teaching hours at school can simplify, facilitate and improve the performance of teaching and learning activities. Teacher teaching hours arrangement is useful to facilitate teaching and learning activities in order to realize neatness in school performance activities. The increasing number of teaching hours, the accuracy required quickly and accurately in data processing can also speed up time. Usually the arrangement of teaching hours for subjects in Vocational High School Adi Luhur 2 (AL 2 Vocational School) is still processed normally and manually and there is still the same data because the teacher concerned teaches more than one school, so it requires a teacher scheduling program that can complete arranging teacher schedules quickly and precisely. For this reason, application programs that can make scheduling of teaching teachers are utilized, so that teacher's teaching schedules do not conflict with teaching schedules in other schools. In this study using Mamdani's Fuzzy Inference System (FIS). With the existence of a teaching schedule management system with the approach of the fuzzy mamdani method more accurately in accordance with the best conditions of the teacher concerned. The results of this study are in the form of a prototype that can process input in the form of a teacher's willingness to set up a teaching schedule at SMK AL 2.
\end{abstract}

Keywords: Schedule of teaching, teacher, mamdani fuzzy logic

\begin{abstract}
ABSTRAK
Pengaturan jam mengajar guru di sekolah dapat mempermudah, memperlancar dan meningkatkan kinerja kegiatan belajar mengajar. Pengaturan jam mengajar guru bermanfaat untuk mempermudah kegiatan belajar mengajar agar terwujud kerapian dalam kegiatan kinerja sekolah. Semakin banyaknya jumlah jam mengajar, maka diperlukan ketepatan secara tepat dan cepat dalam pemprosesan data juga dapat mempercepat waktu. Biasanya pengaturan jam mengajar mata pelajaran di Sekolah Menengah Kejuruan Adi Luhur 2 (SMK AL 2) masih diolah secara biasa dan manual dan masih ada data yang sama dikarenakan guru yang bersangkutan mengajar lebih dari satu sekolah, sehingga perlukan program pengaturan jadwal mengajar guru yang dapat menyelesaikan pengaturan jadwal mengajar guru secara cepat dan tepat. Untuk itu dimanfaatkan program aplikasi yang dapat membuat penjadwalan guru mengajar, agar jadwal mengajar guru tidak terjadi benturan dengan jadwal mengajar di sekolah lain. Dalam penelitian ini menggunakan logika Fuzzy Inference System (FIS) Mamdani. Dengan adanya sistem pengaturan jadwal mengajar dengan pendekatan metode fuzzy mamdani dengan lebih akurat sesuai dengan kondisi yang terbaik dari guru yang bersangkutan. Hasil dari penelitian ini yaitu berupa prototype yang dapat memproses masukan berupa kesediaan guru dalam menatur jadwal mengajar di SMK AL 2.
\end{abstract}

Kata kunci: Jadwal mengajar, guru, logika fuzzy mamdani 


\section{PENDAHULUAN}

Kemajuan aplikasi pada dunia pemograman saat ini begitu sangat cepat, dimana sangat berdampakiterhadap lingkungan kita, seakan semua aktifitas manusia tidak bisa lepas dari yang namanya teknologi. Salah satunya dengan adanya komputer yang dari masa ke masa semakin canggih begitu sangat membantu untuk mewujudkan semua hal yang diperlukan bagi manusia. Berdasarkan manfaat teknologi tersebut yang terus berkembang supaya lebih bermanfaat dan berguna.

Pembagian jam mengajar di sebuah institusi pendidikan dapat menyokong, mendorong dan meningkatkan kemampuan di instutusi pendidikan. Pengaturan jam mengajar guru bermanfaat untuk mempermudah kegiatan belajar mengajar agar terwujud kerapian dalam kegiatan kinerja sekolah. Semakin banyaknya jumlah jam mengajar, maka diperlukan ketepatan secara tepat dan cepat dalam pemprosesan data juga dapat mempercepat waktu, sehingga perlukan program pengaturan jadwal mengajar guru yang dapat menyelesaikan pengaturan jadwal mengajar guru secara cepat dan tepat.

Sistem merupakan kumpulan dari elemn-elemen atau sub sistem yang saling berkaitan satu sama lain yang memiliki tujuan yang sama. Program aplikasi merupakan suatu model yang digunakan sebagai alat memproses data dari suatu permasalahan yang memiliki kompleksifitas yang cukup tinggi dan memerlukan hasil yang cepat dan tepat. Pencapaian tujuan ini menyebabkan timbulnya permasalahan, perubahan yang terus-menerus perlu dikembangkan dan dikendalikan [1].

Sistem Pendukung Keputusan (SPK) sebagai sekumpulan prosedur berbasis model untuk data pemrosesan dan penilaian guna membantu para manajer mengambil keputusan untuk sukses, sistem tersebut haruslah sederhana, cepat, mudah dikontrol, adaptif lengkap dengan isu-isu penting, dan mudah berkomunikasi [2].

Dari maksud diatas, dapat petunjuk menjadi empat khususkan dari SPK, yaitu:

1. SPK menyatukan data dan model menjadi satu kesatuan.

2. Sistem pendukung keputusan dibangun untuk mempermudah para pimpinan (pengambil keputusan) dalam proses menentukan keputusan dari problem yang bersifat kurang terstruktur.

3. SPK sebagai penunjang penilaian pemimpin.

4. Teknik sistem pengambil keputusan diteliti untuk menyokong manfaat daripengambil keputusan.

Program dari sistem pengambil keputusan bisa dikatakan sukses apabila, terdapat kondisi sebagai berikut:

1. Konsistensi dari databases yang banyak, yang dalam penggunaannya masih mengalami kesulitan.

2. Hal yang penting adanya perubahan dan kumputer pada proses tujuan keputusan.

3. Waktu yang singkat, baik dalam penentuan output maupun dalam inputnya

\subsection{Rumusan Masalah}

Dari hal-hal yang telah dikemukakan di atas, maka perumusan masalah dalam aplikasi penjadwalan Guru di SMK AL 2 adalah:

1. Bagaimana "Membangun sistem Penjadwalan Guru Di Sekolah Menengah Kejuruan Adi Luhur 2" yang tepat dan efisien dengan pendekatan logika fuzzy?

2. Penngunaan tenaga manusia untuk membuat data masih manual sehinggga data menjadi tidakk rapi.

3. Sering terjadinya kerancuan dalam penjadwalan guru di sekolah. 
4. Sistem yang masih manual membuat penjadwalan belum efisien.

\subsection{Tujuan}

Penelitian ini memiliki beberapa tujuan diantaranya:

1. Membuat ketepatan dan mempermudah dalam pengaturan jadwal mengajar guru dilihat dari aspek pengoperasian program yang dilandaskan pada kriteria dan bobot yang telah disepakati.

2. Mengimplementasikan logika fuzzy inference system Mamdaniyang dapat digunakan untuk sistem pengaturan jadwal mengajar agar tidak bentrok dengan jadwal yang lain.

3. Menunjang kegiatan belajar mengajar.

4. Mempermudah bagian kurikulum dalam membuat jadwal secara cepat dan tepat menggunakan perhitungan otomatis.

5. Mengatasi masalah dalam penjadwalan yaitu menghindari jadwal guru yang sama pada satu kelas dan pada jam yang sama.

\section{METODE/PERANCANGAN PENELITIAN}

\subsection{Pengertian Fuzzy Logic}

Awalnya kehadiran teori logika fuzzy dinamakan dengan logika tegas yang mengandung nilai true dan false secara kekal. Sebaliknya fuzzy logic adalah suatu nalar yang samar (fuzzyness) antara benar dan salah. Dalam teori fuzzy logic suatu nilai bisa bernilai benar dan salah secara bersamaan. Kebenaran dan kesalahan suatu nilai tergantung pada nilai keanggotaan yang dimilikinya. Manusia yang belum memahami fuzzy logicmengira bahwa fuzzy logic adalah hal yang rumit dan susah di pahami. Tetapi, sekali mengenalnya, ia pasti akaninterestdan akan menjadihal yang baru untuk di dalami. Fuzzy logic adalah suatu cara yang tepat untuk memetakan suatu ruang input ke dalam suatu ruang output [3].

\subsection{LogikaFuzzy Inference System Mamdani}

Logika fuzzy inference system Mamdani atau Metode Max-Min. Metode ini dipopulerkan oleh Ebrahim Mamdani pada tahun 1975. untuk mendapatkan luaran, diperlukan 4 langkah:

1. Pembentukan himpunan fuzzy. Menentukan variabel, himpunan, dan derajat keanggotaan antara data masukan fuzzy dengan himpunan fuzzy.

2. Fungsi implikasi pada logika FIS Mamdani. Fungsi implikasi yang digunakan adalah min untuk menghasilkan ouput infrensi fuzzy.

3. Komposisi Aturan (rule). Infrensi diperoleh dari kumpulan dan korelasi antar aturan. Ada 3 metode yang digunakan dalam melakukan inferensi sistem fuzzy, yaitu: max, additive dan Jumlah babilistik OR.

4. Penegasan (defuzzy). Himpunan fuzzy yang diperoleh dari komposisi rule-rule fuzzy, sedangkan output yang dihasilkan merupakan suatu bilangan pada domain himpunan fuzzy.

Tujuan utama fuzzy logic adalah menggambarkan sebuah ruang input ke dalam ruang output dengan memanfaatkan IF-THEN Rule.Penggambaran dilakukan dalam suatu FIS, langkah-langkah rule bisa sembarang. FIS memeriksa semua rule secara simultan untuk mendapatkan kesimpulan. FIS adalah sebuah metode yang menginterpretasikan harga-harga dalam vektor input, menarik kesimpulan berdasarkan sekumpulan IF-THEN rule yang diberikan, dan kemudian menghasilkan vektor output [4]. 


\section{HASIL DAN PEMBAHASAN}

\subsection{Penerapan Logika}

Disaat kita menyusun penerapan logika fuzzy inference system Mamdani untuk pengaturan jadwal mengajar ini terdapat beberapa step yang harus dilakukan untuk mendapatkan data yang valid dalam penyusunannya.

Setelah dilakukan perhitungan dan percobaan, maka diperoleh hasil pengelolaan tugas mengajar guru di SMK AL 2 dengan menggunakan logika fuzzy inference system Mamdani dengan Matlab.

Menentukan Himpunan Fuzzy

1. Variabel Status Kepegawaian Guru

Variabel input status kepegawaian guru yakni status guru apakah sebagai guru tetap atau sebagai guru tidak tetap, guru tetap lebih ditekankan untuk siap kapan saja dalam mengajar dan stanby di sekolah adapun untuk guru tidak tetap dapat mengatur jadwal mengajar sendiri, dikarenakan guru tidak tetap biasanya mengajar lebih dari satu tempat.Range dan domain dari variabel status kepegawaian guru dapat terlihat pada tabel di bawah ini.

Tabel 1. Variabel Status Kepegawaian Guru

\begin{tabular}{|c|c|c|c|}
\hline No & Himpunan & Range & Domain \\
\hline 1 & Kurang & $1-10$ & $0-4$ \\
\hline 2 & Sedang & $1-10$ & $3-7$ \\
\hline 3 & Baik & $1-10$ & $6-10$ \\
\hline
\end{tabular}

Variabel Status Kepegawaian Guru dibagi menjadi tiga himpunan fuzzy yaitu: Kurang, Sedang, dan Bagus. Keanggotaan fuzzy Kurang akan memiliki domain [0 - 4] dengan derajat keanggotaan Kurang tertinggi (=1) terletak pada angka 0 - 3. Himpunan fuzzy Sedang memiliki domain [3 - 7] dimana derajat keanggotaan Sedang tertinggi $(=1)$ terletak pada nilai 5. Himpunan fuzzy Bagus akan memiliki domain [6 - 10] dengan derajat keanggotaan Bagus tertinggi $(=1)$ terletak pada angka $\geq 7$. Variabel Status Kepegawaian Guru dipresentasikan dengan fungsi keanggotaan bahu dan segitiga. Hasil pengolahan himpunan dengan program Matlab dapat terlihat gambar dibawah ini.

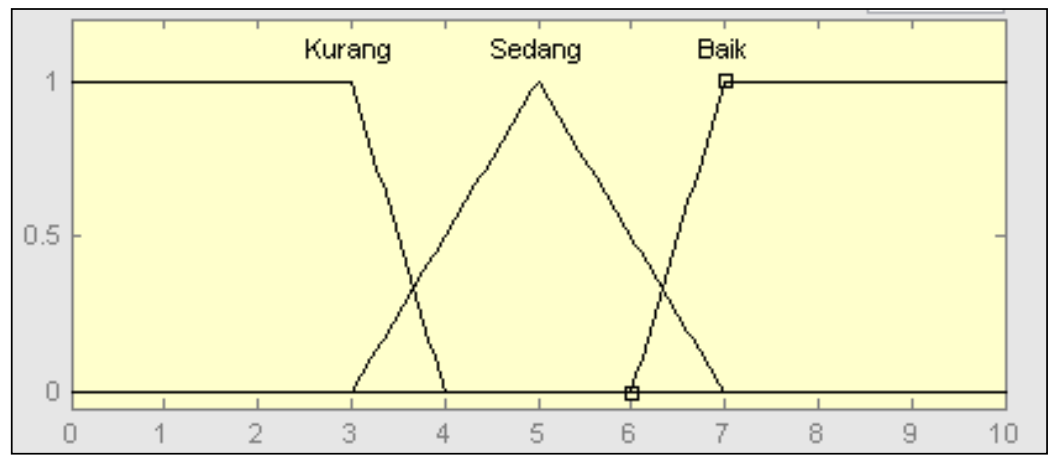

Gambar 1. Variabel Status Kepegawaian Guru

Dan persamaannya.

$$
\begin{aligned}
& \mu \text { Kurang }[\mathrm{x}]= \begin{cases}1 & ; 0 \leq \mathrm{x} \leq 3 \\
(4-\mathrm{x}) /(4-3) & ; 3 \leq \mathrm{x} \leq 4 \\
0 & ; \mathrm{x} \geq 4\end{cases} \\
& \mu \text { Sedang }[\mathrm{x}]= \begin{cases}(\mathrm{x}-3) /(4-3) & ; 3 \leq \mathrm{x} \leq 4 \\
(7-\mathrm{x}) /(4-3) & ; 4 \leq \mathrm{x} \leq 7 \\
0 & ; \mathrm{x} \leq 3 \text { ataux } \geq 7\end{cases}
\end{aligned}
$$


$\mu$ Baik $[\mathrm{x}] \quad= \begin{cases}0 & \mathrm{x} \leq 6 \\ (\mathrm{x}-6) /(10-6) ; & 6 \leq \mathrm{x} \leq 7 \\ 1 & ; 7 \leq \mathrm{x} \leq 10\end{cases}$

\section{Variabel Kinerja Guru}

Variabel input kinerja guru yaitu tingkat kebaikan guru dalam mengajar, berprilaku, dan disiplin di sekolah. Semakin baik kinerja guru tersebut, maka guru tersebut mendapatkan keistimewaan dalam menentukan jadwal mengajar baik hari dalam mengajar maupun jam mengajar. Apabila kinerja guru tersebut kurang baik, maka pihak sekolah yang akan mengatur penuh jadwal mengajar guru tersebut, sebagai hukuman demi peningkatan kinerja. Range dan domain dari variabel kinerja guru dapat terlihat pada tabel di bawah ini.

Tabel 2. Variabel Kinerja Guru

\begin{tabular}{|c|c|c|c|}
\hline No & Himpunan & Range & Domain \\
\hline 1 & Kurang & $1-10$ & $0-4$ \\
\hline 2 & Sedang & $1-10$ & $3-7$ \\
\hline 3 & Baik & $1-10$ & $6-10$ \\
\hline
\end{tabular}

Variabel kinerja guru memiliki 3 himpunan fuzzy diantaranya: Kurang, Sedang, dan Bagus. Himpunan fuzzy Kurang akan memiliki domain [0 - 4] dimana derajat keanggotaan Kurang tertinggi (=1) terletak pada angka 0 - 3. Himpunan fuzzy Sedang memiliki domain [3 - 7] dimana derajat keanggotaan Sedang tertinggi $(=1)$ terletak pada nilai 5. Himpunan fuzzy Bagus akan memiliki domain [6 - 10] dimana derajat keanggotaan Bagus tertinggi $(=1)$ terletak pada angka $\geq 7$. Variabel kinerja guru dipresentasikan dengan fungsi keanggotaan bahu dan segitiga. Hasil pengolahan himpunan dengan program Matlab dapat terlihat seperti pada gambar di bawah ini.

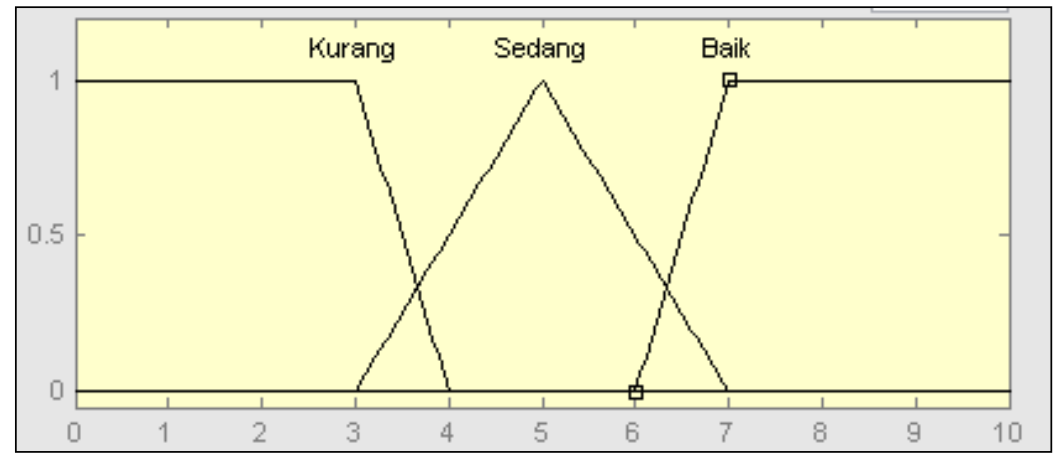

Gambar 2. Grafik Variabel Kinerja Guru

Dan persamaannya.

$$
\begin{aligned}
& \mu \text { Kurang }[\mathrm{x}]= \begin{cases}1 & ; 0 \leq \mathrm{x} \leq 3 \\
(4-\mathrm{x}) /(4-3) & ; 3 \leq \mathrm{x} \leq 4 \\
0 & ; \quad \mathrm{x} \geq 4\end{cases} \\
& \mu \text { Sedang }[\mathrm{x}]= \begin{cases}(\mathrm{x}-3) /(4-3) & ; 3 \leq \mathrm{x} \leq 4 \\
(7-\mathrm{x}) /(4-3) & ; 4 \leq \mathrm{x} \leq 7 \\
0 & ; \mathrm{x} \leq 3 \text { ataux } \geq 7\end{cases}
\end{aligned}
$$




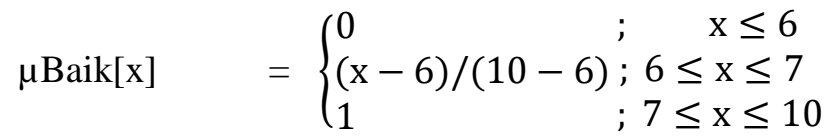

3. Variabel Jarak Tempat Tinggal

Variabel input jarak tempat tinggal yaitu, semakin jauh guru tersebut tinggal dari jarak ke sekolah, maka guru tersebut memiliki keistimewaan lebih dalam menentukan jadwal mengajar di sekolah dikarenakan guru yang memiliki tempat tinggal lebih jauh dari sekolah akan lebih lama datang ke sekolah. Untuk menghindari terlambat datang ke sekolah, maka guru tersebut lebih tahu berapa lama perjalanan dari tempat tinggal ke sekolah. Range dan domain dari variabel jarak tempat tinggal dapat terlihat pada tabel di bawah ini.

Tabel 3. Variabel Jarak Tempat Tinggal

\begin{tabular}{|c|c|c|c|}
\hline No & Himpunan & Range & Domain \\
\hline 1 & Kurang & $1-10$ & $0-4$ \\
\hline 2 & Sedang & $1-10$ & $3-7$ \\
\hline 3 & Baik & $1-10$ & $6-10$ \\
\hline
\end{tabular}

Variabel jarak tempat tinggaldibagi menjadi 3 himpunan fuzzy yaitu: Kurang, Sedang, dan Bagus. Himpunan fuzzy Kurang akan memiliki domain [0 - 4] dimana derajat keanggotaan Kurang tertinggi $(=1)$ terletak pada angka $0-3$. Himpunan fuzzy Sedang memiliki domain [3 7] dimana derajat keanggotaan Sedang tertinggi $(=1)$ terletak pada nilai 5. Himpunan fuzzy Bagus akan memiliki domain [6 - 10] dimana derajat keanggotaan Bagus tertinggi $(=1)$ terletak pada angka $\geq 7$. jarak tempat tinggal dipresentasikan dengan fungsi keanggotaan bahu dan segitiga. Hasil pengolahan himpunan dengan program Matlab dapat terlihat seperti pada gambar di bawah ini.

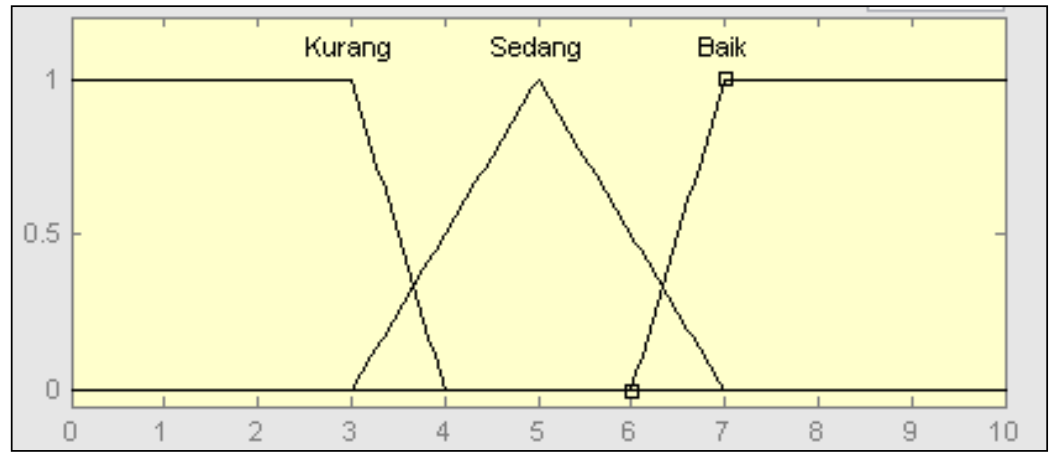

Gambar 3. Grafik Variabel Jarak Tempat Tinggal

Dan persamaannya.

$\mu$ Kurang $[\mathrm{x}]= \begin{cases}1 & ; 0 \leq \mathrm{x} \leq 3 \\ (4-\mathrm{x}) /(4-3) & ; 3 \leq \mathrm{x} \leq 4 \\ 0 & ; \quad \mathrm{x} \geq 4\end{cases}$
$\mu$ Sedang $[\mathrm{x}]= \begin{cases}(\mathrm{x}-3) /(4-3) & ; 3 \leq \mathrm{x} \leq 4 \\ (7-\mathrm{x}) /(4-3) & ; 4 \leq \mathrm{x} \leq 7 \\ 0 & ; \mathrm{x} \leq 3 \text { ataux } \geq 7\end{cases}$ 


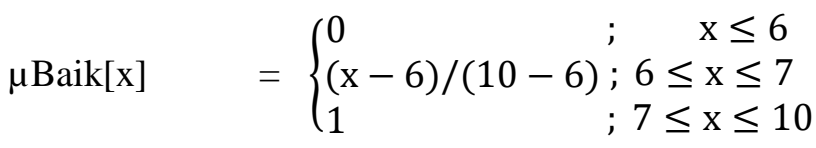

\subsection{Proses Mamdani}

Dalam proses mamdani terdapat beberapa tahapan yang harus dilakukan diantaranya:

\subsubsection{Fuzzifikasi}

Fungsi derajat keanggotaan yang digunakan adalah linier turun, segitiga, dan linier naik.

Di bawah ini merupakan fungsi derajat keanggotaan dari variabel-variabelnya:

- $\mathrm{HFT}=1$

- PHFT $=0,66$

- $\mathrm{HFT}=1$

- $\mathrm{HFT}=0,73$

- $\mathrm{HFT}=0,71$

- HFT $=0,66$

- $\mathrm{HFT}=1$

- HFT $=1$

- HFT $=0,75$

*Ket: HFT (Himpunan Fuzzy Tinggi)

HFN (Himpunan Fuzzy Normal)

\subsubsection{Rules:}

Pembentukan rule editor, yaitu tempat dimana rule-rule dikelola, baik itu untuk menambah, menghapus, dan juga mengubah rule. Pada rule editor lah rule dikelola agar nantinya sistem dapat menghasilkan Output sesuai dengan yang Input yang dilakukan pada variabel-variabel Input.Rule yang telah ditetapkan memiliki 22 Rule.

\subsubsection{Fungsi Implikasi}

Dalam hal ini fungsi yang digunakan adalah metode min dan rule yang terpengaruh adalah rule 21 dan rule 22 .

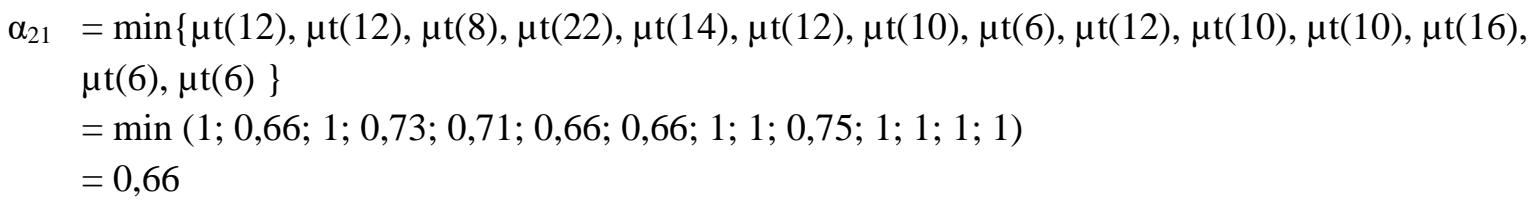

Berdasarkan fungsi keanggotaan dari Variabel Output himpunan tinggi, pada saat $\alpha_{21}=0,66$ diperoleh nilai:

$$
\begin{aligned}
& \mu \mathrm{b}=\left(\mathrm{d}_{21}\right)=\alpha_{21} \quad \underbrace{\mathrm{d}[21]-3}_{7}=0,66 \\
& \mathrm{~d}[21]=4,62+3 \quad=7,62 \\
& \alpha_{22}=\min \{\mu \mathrm{t}(12), \mu \mathrm{t}(12), \mu \mathrm{t}(8), \mu \mathrm{t}(22), \mu \mathrm{t}(14), \mu \mathrm{t}(12), \mu \mathrm{t}(10), \mu \mathrm{t}(6), \mu \mathrm{t}(12), \mu \mathrm{t}(10), \mu \mathrm{t}(10), \\
& \mu \mathrm{t}(16), \mu \mathrm{t}(6), \mu \mathrm{t}(6)\} \\
& =\min (1 ; 0,66 ; 1 ; 0,73 ; 0,71 ; 0,66 ; 0,2 ; 1 ; 1 ; 0,75 ; 1 ; 1 ; 1 ; 1) \\
& =0,2
\end{aligned}
$$


Dari fungsi keanggotaan variabel Output himpunan tinggi, pada saat $\alpha 22=0,2$ diperoleh hasil:

$$
\begin{array}{lll}
\mu \mathrm{b}=\left(\mathrm{d}_{22}\right)=\alpha_{22} \longleftrightarrow \frac{\mathrm{d}[22]-3}{7}=0,2 & \\
\mathrm{~d}[22]=1,4+3 & =4,4
\end{array}
$$

\subsubsection{Komposisi Aturan}

Metode Max digunakan untuk menetukan komposisi aturan.

Variabel Output

Derajat kebenaran himpunan BAIK

$=\operatorname{Max}\left(\alpha_{21} ; \alpha_{22}\right)$

$=\operatorname{Max}(0,66 ; 0,2) \quad=0,66$

Daerah hasil inferensi tertinggi adalah 0,66 dan terendah 0,2

\subsubsection{Defuzzyfikasi}

Metode untuk fuzzyfikasi adalah centroid.

$$
\begin{aligned}
& \mu(\mathrm{x}) \quad=\left\{\begin{array}{c}
0,2 ; 4,4 \leq d_{21} \leq 7,62 \\
0,66 ; 7,62 \leq d_{21} \leq 10
\end{array}\right. \\
& \mathrm{M} 1=\int_{4,4}^{7,62}(0,2) x d x \\
& =0,1 \mathrm{x}^{2} \mid \begin{array}{l}
7,62 \\
4,4
\end{array}=5,81-1,9=3,91
\end{aligned}
$$

$$
\begin{aligned}
\text { M2 } & =\int_{7,62}^{10}(0,66) x d x \\
& =0,\left.33 \mathrm{x}^{2}\right|_{7,62} ^{10}=33-19=14
\end{aligned}
$$

$\mathrm{L} 1=0,2 \quad(7,62-4,4)=0,6$

$$
\mathrm{L} 2=0,66(10-7,62) \quad=1,5
$$

Nilai crisp output dihitung dengan:

$\mathrm{z}^{*}=\frac{M_{1}+M_{2}}{A_{1}+A_{2}}=\frac{14+3,91}{0,6+1,5}=8,53$

Melalui hasil pengolahan dengan pendekatan metode fuzzy. Kita dapat mengetahui pengaturan jadwal mengajar guru secara cepat dan tepat. Semakin besar nilai yang dimiliki guru tersebut, apabila ada lebih dari satu guru yang memiliki jadwal mengajar di hari, jam, dan kelas yang sama, maka guru yang memiliki nilai akan lebih diutamakan untuk mengajar di kelas tersebut.

\subsection{Implementasi Program}

Pengujian program pada penelitian ini menggunakan sofware Matlab dalam menerapkan logika fuzzy inference system Mamdani untuk pengelolaan tugas guru dalam mengajar di SMK AL 2. Berikut adalah hasil implementasi logika fuzzy inference system Mamdani. Tahapan-tahapan yang perlu dilakukan diantaranya: 
1. Pembentukan rule editor, yaitu tempat dimana rule-rule dikelola, baik itu untuk menambah, menghapus, dan juga mengubah rule. Pada rule editor lah rule diolah agar kedepannyaa sistem dapat menghasilkan output sesuai dengan yang input yang dilakukan pada variabelvariabel input.

2. Pembuatan prototyping yang merupakan bagian dari produk yang mengekspresikan logika maupun fisik antarmuka eksternal yang ditampilkan [5]. Tampilan GUI yangmerupakan tampilan hasil eksekusi program dan tempat memasukkan nilai pada tiap-tiap variabel input. Setelahnya dapat dilihat hasil atau output dari program tersebut. Tampilanaplikasi pengaturan jadwal mengajar guru dengan pendekatan logika FIS mamdani dapat dilihat pada gambar di bawah ini.

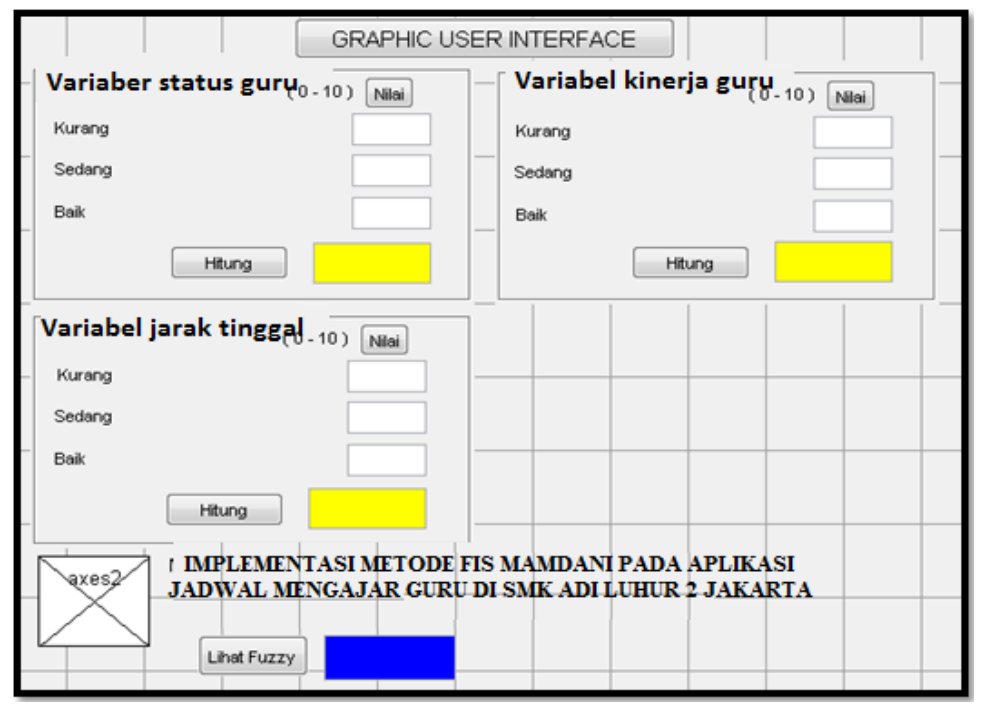

Gambar 4. Graphic user interface

\section{KESIMPULAN DAN SARAN}

Hal-hal yang dapat disimpulkan dari penelitian ini diantaranya:

1. Penggunaan logika fuzzy inference system Mamdani untuk mengatur tugas guru dalam mengajar di SMK AL 2, sehingga tidak terjadi tumpang tindih jadwal mengajar dengan guru yang lain dapat menggunakan Matlab R2009b dalam pemodelan sistemnya yang biasanya Matlab dimanfaatkan sebagai pendukung research, sehingga bisa diperluas dengan menggunakan pemograman lainnyacontohnya java dan PHP dan lain sebagainya agar bisa di gunakan di masyarakat.

2. Penerapan logika fuzzy inference system Mamdani di sini hanya sebatas mengatur jadwal mengajar guru di SMK AL 2 tidak sampai pada pengambilan keputusan.

3. Kriteria dalam pertimbangan keputusan dalam mengatur jadwal mengajar guru menggunakan tiga macam kriteria, yaitu variabel status kepegawaian guru, variabel kinerja guru, dan variabel jarak tempat tinggal guru.

\section{DAFTAR PUSTAKA}

[1] Marimin, dan Nurul. (2010) Aplikasi Teknik Pengambilan Keputusan dalam ManajemenRantai Pasok, IPB Press, Bogor.

[2] Efraim Turban, Jay E. Aronson, and Ting-Peng Liang. (2005). Decision Support System And Intelligent System-7th Ed. Pearson Education, New Jersey:Inc. Upper Saddle River. 
PETIR: Jurnal Pengkajian dan Penerapan Teknik Informatika

Vol. 12, No. 2, September 2019, P-ISSN 1978-9262, E-ISSN 2655-5018

[3] Kusumadewi, Sri, et al. (2006). Fuzzy Multi- Attribute Decision Making (Fuzzy MADM).Yogjakarta: Graha Ilmu.

[4] Eng, Agus Naba. (2009). Belajar Cepat Fuzzy Logic menggunakan Matlab. Yogyakarta: Andi Offset.

[5] Simarmata, Janner. (2010).Rekayasa Perangkat Lunak. Yogyakarta: Andi Offset. 